Hamid Taieb, “The Early Husserl on Typicality”, in Arnaud Dewalque, Charlotte Gauvry, Sébastien Richard (eds.), Philosophy of Language in the Brentano School, Palgrave Macmillan, Cham, 2021, p. 263-278.

\title{
The Early Husserl on Typicality
}

\author{
Hamid Taieb
}

\begin{abstract}
This paper presents and evaluates the early Husserl's account of typicality. In the Logical Investigations, Husserl holds that the meaning of ordinary language (common) names is sensitive to typicality: this meaning depends on typical examples which vary in different contexts and are more or less similar to one another. This seems to entail that meanings, which according to Husserl are concepts, are "fluctuating" (schwankend) and vague. Prima facie, such a claim contravenes his theory of ideal meanings, or concepts, which are "fixed" (fest) and sharp. However, Husserl wants to save this theory. He claims that the fluctuation and vagueness in question are not to be found in the meaning itself, or the concept, but rather derive from the act of meaning. Thus, he apparently manages to make room for typicality in ordinary language while accepting only fixed and sharp meanings. After presenting Husserl's theory, I evaluate it and ask whether he will still be committed, despite his own claims, to accepting prototype concepts to account for typicality in ordinary language.
\end{abstract}

\section{Introduction: Some Typicalities}

As philosophers, we are - or at least we have been for a very long time - the victims of a "definitionalist prejudice", in both our semantics and our theory of concepts. We have tended to think that our (common) names refer to things by expressing meanings, or concepts, which are structured like definitions. On this view, "man", for example, refers to men by the intermediary of a meaning, or concept, which represents a series of "necessary and sufficient" features that all and only men possess. In this respect, all items meant by the name, or gathered together by the concept, are strictly identical. This vision of the meanings of words and of the content of concepts as having "definitional structure" is said to be inherited from 
Plato; at any rate, it has circulated for a very long time among philosophers without being contested (on all this, I follow Margolis \& Laurence 1999 and 2019; for the reference to Plato, see 1999: 10).

In the second half of the twentieth century, however, this image came under intense criticism. Some cognitive scientists defended the thesis that our concepts, and by their intermediary our names, gather together not identical things, but more or less similar ones, which are organized around a "prototypical case" - that is, a sort of standard which things within the extension resemble more or less. They also held that the extension of such concepts - called "prototype concepts" - is vague, since things can be less and less similar to the prototype without there being any sharp boundary that can be drawn as to where something is no longer included in the class. This theory is meant to develop Wittgenstein's notion of "family resemblances", which states that our concepts have - and our words refer to - an extension made of more or less similar items and which lacks sharp boundaries (Rosch \& Mervis 1975 and Hampton 1995, following Wittgenstein 1953; on this whole narrative about concept structure, see again Margolis \& Laurence 1999 and 2019).

An interesting development about prototype concepts is the thesis that they are context-sensitive. Depending on the context in which we are using a name and mobilising a given concept, the standard that we use to fix the extension will vary. For example, if someone tells us that "Stacey volunteered to milk the animal whenever she visited the farm," we will take a cow as the model of an animal, whereas when someone says "Frank asked her father to let her ride the animal," the model that we will take is a horse. Thus, in the first case, the concept will be about "cow-like living beings", but in the second case it will be about "horse-like living beings". (The view and the examples are from Roth \& Shoben 1983, quoted in Del Pinal 2016: 2911-2912; see also Prinz 2012.) This not only shows that the definitionalist is wrong to think that we have a strictly delimited series of features in mind when applying names and concepts, since we have at best typical cases and blurred boundaries around them. It also reveals that even our models for the fixing of extension vary from one situation to another. According to this view, a concept is a "rich arrays of information" stored in "long-term memory" and "the subsets of features activated in each token use can vary" (Del Pinal 2016: 2912). In other words, prototype concepts are mental representations: they are understood as cognitive "entries" storing "information". So in the debate on the ontology of concepts, when it is asked whether concepts are Fregean-like abstract entities or rather mental representations, defenders of the prototype view clearly opt for the latter. (For an overview of this debate, see Margolis \& Laurence 2019.) 
As indicated, the usual source which is mentioned when people treat of the origins of the prototype theory is Wittgenstein's notion of family resemblances (Rosch \& Mervis 1975). However, as emphasized by Mulligan (1990 and 2012), Wittgenstein's theory of family resemblances had been anticipated by Austro-German authors, in particular Brentano and his heirs. More specifically, the very idea that the reference of names and the extension of concepts is fixed on the basis of typical cases had been explicitly defended by authors in the Austro-German tradition long before Wittgenstein: one finds in Marty (1908: 527-531), at the turn of the twentieth century, the idea that (common) names in ordinary language have as their meaning a "concept built following a type". Similarly, the late Husserl holds that our non-scientific concepts are "type concepts" expressed by ordinary language (1939 and 2012). ${ }^{1}$ Alexius Meinong (1969: 480-492) also hints at a similar theory of concepts. In fact, the idea that our concepts might have not a definitional, but rather a typical structure was quite widespread in the German-speaking world. It was seemingly introduced by the German philosopher Benno Erdmann (1894), who himself relied on the work of William Whewell (1858). Besides Marty, the late Husserl, and Meinong, it seems that prototype concepts were accepted by Wilhelm Jerusalem (1902: 98-103) and by Johannes von Kries (1916: 10-13). ${ }^{2}$

Interestingly, the early Husserl, in his first Logical Investigation, also defends the view that our ordinary language is sensitive to typicality. More precisely, he holds that our (common) names refer to more or less similar things organised around a typical case, which is itself context-dependent, and that the limits of their application is vague. Apart from Benoist (2010), his views have never been compared with contemporary prototype theories. It is notable, however, that the early Husserl explains the same phenomena that the prototype theory is meant to explain, but without admitting type concepts: rather, he thinks that typicality is a linguistic feature found at the level of ordinary language, and that it is connected with fluctuations in our acts of meaning or so-called "meaning-intentions". Concepts, he maintains, are abstract, "ideal" entities which have definitional structure. This is an interesting move, as it seems to suggest that what people have taken to be a feature of our concepts might in fact be a merely linguistic phenomenon which can be explained while leaving the structure of concepts untouched. Moreover, in order to explain it, it is not

\footnotetext{
${ }^{1}$ On these issues in Marty, as well as their anticipation in Brentano (see Taieb 2020). On similar topics in the later Husserl, see "The Structure and Domain of (Proto)type Concepts: A Husserlian Approach" (Taieb Ms.). In the present article, I focus on the early Husserl, whose theory, interestingly, differs not only from those of Brentano and Marty, but also from his own later account.

${ }^{2}$ I thank Mark Textor for the reference to Jerusalem. On Von Kries, see the various discussions in Mulligan 2012.
} 
necessary to treat concepts as mental representations, for typicality can still be accounted for even if, from an ontological point of view, concepts are described as abstract entities.

In this paper, I will present and evaluate the early Husserl's account of typicality. In the first section, I will briefly introduce the later Husserl's view on types, in order to contrast this with his earlier account. In the second, longest section, I will present in detail the early Husserl's views on typicality. In the third section, I will evaluate his position, by asking whether his earlier account can do without prototype concepts. I will answer that it cannot, and that this might explain why Husserl later adopted a theory of type concepts.

\section{A Brief Excursus: The Later Husserl on Type Concepts}

The late Husserl thinks that the concepts that we build in our ordinary life are "type concepts" (Typenbegriffe) (Husserl 1939 and 2012; on his theory, see Lohmar 1998 and Bégout 2002). These concepts pick out "commonalities" (Gemeinsamkeiten) in "open groups of similarity" (Husserl 2012: 233.25-32). Their extension seems to be a network of more or less similar things: Husserl states that types have a "horizon of sameness, of similarity" (Husserl 2012: 388.8-10). But although these concepts group together more or less similar items, it is unclear where to put their exact boundary, that is, the level of similarity at which something will no longer be included in the class. Husserl describes these types as "vague generalities", holding that their extension lacks determinate boundaries (Husserl 1939: 114; see also Bégout 2002: $60)$.

The later Husserl treats type concepts as psychic items, since they are mental representations built on the basis of our ordinary experience (Husserl 1939). Type concepts are opposed to abstract, ideal concepts, which are grounded on the identity (rather than similarity) of their members and are exact (rather than vague), that is, they have sharply delimited extensions (Husserl 2012; for the late Husserl's admission of "empirical scientific concepts" in addition to ideal concepts and type concepts, see 2012: 250.9-31). While it is clear that typicality is a feature of concepts, the late Husserl also claims that it is mirrored at the linguistic level. In fact, he holds that type concepts find their expression in "natural language" (natürliche Sprache) (2012: 276.15 and 315.21-23). ${ }^{3}$ Although I have not found a text where this is clearly stated, his idea might be that our ordinary language (common) names refer to more or less similar items and have vague boundaries of application. At any rate, this would be in line with his earlier views on typicality, developed in the Logical Investigations,

\footnotetext{
${ }^{3}$ As indicated, I explore Husserl's theory of type concepts in my paper "The Structure and Domain of (Proto)type Concepts: A Husserlian Approach".
} 
where he states that the meaning of our ordinary (common) names is sensitive to typicality that is, it is based on more or less similar typical examples - and has vague boundaries. However, the interesting point is again that the early Husserl explains typicality without admitting type concepts. The only concepts that exist are ideal concepts, with definitional structure. This is a more parsimonious view, which I will now present, before considering whether the view is in fact too parsimonious, and whether type concepts are still required in order to account for typicality at the linguistic level.

\section{The Early Husserl's Account of Typicality}

The context in which Husserl discusses typicality are the chapters in the Logical Investigations devoted to "ambiguous expressions". Ambiguous expressions include "essentially occasional expressions", that is, indexicals, whose meanings are constantly renewed in different situations of utterance, and "equivocal terms", that is, words with different meanings, but which are limited in number and fixed in advance and not on the basis of the situation - for example, "dog", "which sometimes means a type of animal, and at other times a foot or a grate" (see $§ \S 24-29$ of the first Logical Investigation; trans. Findlay).

In addition to "essentially occasional expressions" and "equivocal terms", Husserl (1984: 93.5-94.6) counts among ambiguous expressions "vague" ones, namely, (common) names used in daily life, such as "tree", "shrub", "animal", and "plant". The meaning of such terms is said to "fluctuate" (schwanken). Their meaning depends on "typical examples":

Vague expressions have no single meaning-content, the same in all cases of their application: their meaning is oriented towards typical examples, only partially conceived with clearness and definiteness, typical examples which tend to vary from case to case, perhaps even in a single train of thought. The examples, stemming from what are, or from what seem to be, genuinely unified fields, yield a number of concepts, more or less cognate or related, which emerge in turn according to the circumstances of our talk and its varied thought-promptings. (Husserl 1984: 93.11-21; trans. Findlay, slightly modified)

Note that Husserl makes a distinction between the meaning of what he calls a "universal name" (universeller Name) and its extension: the meaning is a concept, whereas the extension is made up of the things that fall under the concept (1984: 51.25-55.33). As regards vague names, their meaning seems to vary following "typical examples" (typische Beispiele). But what are exactly these typical examples? 
Unfortunately, Husserl does not say much more about this. However, when he discusses these issues, he gives as reference on types a paper by Erdmann (1894; see Husserl 1984: 94 n. 1). Now, in the paper in question, Erdmann does not talk of Beispiele, but of Muster, translating with this the term the word "example" found in Whewell (1858). What are "examples" for Whewell? According to him, every class is organized around a type, which is "an example $[\ldots]$ eminently possessing the characters of the class". This might be a "species" for a "genus", or a "genus" for a "family"; that is, it is a general entity directly subordinated to the class of which it is the type. ${ }^{4}$ So, a genus, for example, is made up of a series of species, with one of them being the type, and the others resembling it more or less, with no clear criterion as to where to stop the resemblance series (1858, vol. 2: 121-122).

Is the same point to be found in Husserl? Husserl holds that the meanings of words such as "animal" vary and are "oriented towards typical examples". He adds that the "examples [...] yield a number of concepts, more or less cognate or related" (diese Beispiele [...] bestimmen verschiedene, aber in der Regel verwandte oder beziehungsvolle Begriffe). So, apparently the meaning of the term "animal" varies and orients itself following examples to which there correspond concepts. It would certainly be a reasonable interpretation to hold that the examples in question are, e.g. cow or horse, as in Whewell - that is, general entities directly subordinated to the class of which they are typical examples.

Husserl says that the concepts which correspond to the typical examples are "more or less cognate or related". Does he mean that they are more or less similar in terms of content? In that case, the word "animal", for example, would have as its meaning a series of more or less similar contents: 'cow', 'horse', etc. Seemingly, a word such as "animal" would then refer to more or less similar things because it means more or less similar contents, which vary depending on the context. At any rate, Husserl's idea seems to be that "animal" means 'cow', or 'horse', or some other kindred concept, and that the fixing of the exact meaning depends on the context of utterance. ${ }^{5}$

\footnotetext{
4 This resembles the way prototypes are understood in contemporary philosophy, namely, as subordinated concepts (see Margolis \& Laurence 1999: 28 n. 35). Although Whewell does not say what the item in question would be for a most specific species (e.g. English Cocker Spaniel), one option would be to hold that it is still a general entity, although not a species in the sense of a natural kind (e.g. an English Cocker Spaniel of a certain colour and shape).

${ }^{5}$ Note that Husserl has a limited account of contextualism: the variation of meaning seems to be restricted to entities directly subordinated to the same class. There is a stronger sense of contextualism in contemporary philosophy of language, in which there is no limitation as to the variation that the meaning of a word can undergo in different contexts (on contextualism, see Recanati 2012).
} 
Husserl holds that the application of words of ordinary language comes with borderline cases. He seems to do so when he talks of "expressions standing for relatively simple genera and species of phenomenal properties", such as names of colours:

Within certain ranges and limits their application is unhesitant, i.e. in fields where the type appears clearly, where it can be evidently identified and evidently distinguished from remotely unlike characters, e.g. "signal-red" and "coal-black", andante and presto. But these fields have vague borders, and flow over into correlative spheres comprehended in the same genus, and so give rise to transitional regions where application varies and is wholly uncertain. (Husserl 1984: 93.34-94.6; trans. Findlay)

Clearly, then, "vague names" are vague because the domain of their application has blurred boundaries: that is, there are cases in which it is unclear whether or not the word applies to, for example, some specific reddish colour.

Now, Husserl has a problem with these fluctuations of meaning. Indeed, he has a theory of "ideal meanings". Ideal meanings are, for Husserl, atemporal, abstract objects, divided into concepts and propositions, which constitute, respectively, the meanings of (common) names and of sentences. These meanings are instantiated as parts of our mental acts when we use names and sentences. As ideal entities, however, they exist independently of being instantiated, and as such are Platonic-like universals (see, among others, 1984: 104.21-106.32 and 617.34-618.1, as well as Simons 1995). Now, since these meanings are independent of their being thought, it is unclear in what sense there could be any sort of "fluctuation of meaning". Aren't meanings stable, or "fixed" (fest), atemporal entities? But then, what is to be said about ambiguous expressions, including terms of ordinary language, whose meanings change depending on the context? Hence there arises a problem, one which is explicitly addressed by Husserl:

We have now to consider whether these important facts of fluctuation of meaning are enough to shake our conception of meanings as ideal (i.e. rigorous) unities, or to restrict its generality significantly. Those ambiguous expressions we called essentially subjective, in particular, as also our distinction between vague and exact expressions, might make us doubtful on this point. Do meanings themselves divide into objective and subjective, into meanings fixed (feste) and meanings changeable on occasion? Must we, in other words, so interpret this difference, with seeming obviousness, that it becomes one between meanings that are ideal unities, on the one hand, fixed species untouched by the flux of our subjective picturing and 
thinking, and such, on the other hand, as live submerged in the flux of subjective mental experiences, and are transitory events, at one time there, and at the next moment not? (Husserl 1984: 94.18-95.3; trans. Findlay)

Husserl's answer is straightforward: "variations in meanings" (das Schwanken der Bedeutungen) are in fact "variations in the act of meaning" (Schwanken des Bedeutens), also called "meaning-intentions" (Bedeutungsintentionen). In other words, what fluctuates are our meaning-intentions, not the meanings themselves.

How should we understand this? First of all, the meaning meant in this or that case is always an ideal meaning. In fact, Husserl thinks that even "essentially occasional expressions" - that is, indexicals - could be replaced by objective expressions. All circumstance-sensitive words ("subjective expressions") have equivalent circumstanceunsensitive words ("objective expressions") in terms of which they could be expressed, which would establish a firm relation between the word and the ideal meaning, connected by one and the same meaning-intention:

(...) the content meant by the subjective expression, with sense oriented to the occasion, is an ideal unit of meaning in precisely the same sense as the content of a fixed expression. This is shown by the fact that, ideally speaking, each subjective expression is replaceable by an objective expression which will preserve the identity of each momentary meaning-intention. (Husserl 1984: 95.5-11; trans. Findlay)

Husserl's claim is that everything that is pointed at by means of language is not just describable in relation to the occasion of utterance, but absolutely determinable. "This", "that", "here", "there" are all translatable into objective expressions:

What is, has its intrinsically definite properties and relations, and if it has natural, thinglike reality, then it has also its quite definite extension and position in space and time, its quite definite ways of persisting and changing. But what is objectively quite definite, must permit objective determination, and what permits objective determination, must, ideally speaking, permit expression through wholly determinate word-meanings. (Husserl 1984: 95.20-29; trans. Findlay)

In short, the linguistic phenomenon of ambiguity in general is avoidable, at least "ideally speaking", since Husserl (1984: 95.12-16; trans. Findlay) recognizes that this is 
"impracticable", or even impossible - by this he probably means impossible for us human beings, perhaps due to the fact that such determinations are infinite.

At any rate, this "objectivability" applies all the more to vague names. Although the meaning of "animal" changes depending on the context, it is in each case an ideal, stable meaning that is expressed. What seems to happen is that the meaning switches from one typical case to another depending on the context, so that "animal" means, in turn, 'cow', 'horse', etc. On such a view, there is no distinction between meanings understood as "fixed species untouched by the flux of our subjective picturing and thinking" and meanings understood as "transitory events, at one time there, and at the next moment not" and "submerged in the flux of subjective mental experiences". Husserl can thus say: "Plainly therefore, considered as such, meanings do not differ essentially among themselves" (Husserl 1984: 96.14-16; trans. Findlay).

But then how can we make sense of the claim that vague names "change their meaning" from one context to the other? As indicated above, what is in fact changing is not the meaning itself, but the meaning-intention, or the ascription of meanings to words:

Actual word-meanings are variable, often changing in a single spell of thought, by their nature mainly adjusted to the occasion. Rightly seen, however, such change in meanings is really change in the act of meaning. In other words, the subjective acts which confer meaning on expressions are variable, and that not merely as individuals, but, more particularly, in respect of the specific characters in which their meaning consists. (Husserl 1984: 96.16-23; trans. Findlay)

The idea seems to be that a speaker can ascribe different meanings to "animal" (for example) on different occasions; these variations, however, do not affect the nature of the meanings themselves, which all remain fixed.

It seems clear that for Husserl, the concepts which are meant by the various uses of a vague name have definitional structure and are sharp. The meanings which are mobilised when a vague name is used are based on different typical examples. As Husserl says, these examples "yield a number of concepts, more or less cognate or related". Now, these concepts clearly seem to be both definitional and sharp: they are "firmly determinate word-meanings" and they represent "firmly determinate properties and relations" of things; the words which mean them are "expressions having exact meanings" (Husserl 1984: 95.17-96.3; trans. Findlay, slightly modified). In short, all objects are made up of a precise number of 
determinate features and the concepts which represent these objects mirror these features exactly. Meanings are thus definitional and sharp concepts. For the early Husserl, there is nothing like a type concept.

\section{Evaluation}

The early Husserl makes room for certain phenomena that the prototype theory of concepts is also meant to explain. He accepts that in ordinary language, the meaning of our (common) names depends on typical cases which vary according to the context. He seems to think that these various cases are more or less similar to one another, or at least that they are "more or less cognate or related". He also holds that the limits of the application of these words are vague, since they are cases in which it is not clear whether the word still applies or not. Strikingly, however, whereas contemporary philosophers modify the structure of our concepts to account for this, Husserl maintains that all these linguistic phenomena can be explained by means of fluctuations in meaning-intentions. This is an interesting solution, inasmuch as it tries to explain in purely linguistic terms phenomena that people usually try to account for by modifying the structure of our concepts. Indeed, for Husserl, one and the same word has various meanings (e.g. "animal" means 'cow', 'horse', etc.), depending on the context. These variations are attributed to the shifts in the meaning-intentions, or the ascription of meanings to words, while the meanings themselves which are expressed are all definitional and sharp concepts.

But is Husserl's avoidance of type concepts plausible when explaining typicality? All things considered, I would say that it is not. First of all, one point which is not clear in Husserl's text is whether the meaning of, for example, "animal" is equivalent to that of the names of typical examples, such as "cow", "horse", etc., depending on the various contexts of utterance, or whether it is broader than these specific names, which merely fix the standard of resemblance, in which case the word will mean in turn 'cow-like living beings', 'horse-like living beings', etc. (as in Roth \& Shoben 1983 and Del Pinal 2016, quoted in the Introduction above). I would tend to go for the second option, for otherwise "animal" on the one hand, and "cow", "horse", etc. on the other, would be mere synonymous terms in various contexts, which would be an unfortunate result, since the first is obviously the name of a genus, the others of species. It seems therefore that the meaning of vague names should include some sort of open range of similarities. However, the early Husserl owes us an explanation of how exactly this will work, all the more so in the context of a theory which admits ideal meanings, which have definitional structure and are sharp. 
Moreover, and independently of this issue, it seems to me that the way vague names are supposed to work in Husserl in fact requires the existence of underlying type concepts. Husserl's account seems to imply that to every vague name there corresponds some information stored in the memory of the utterer. Indeed, he would agree that people apply "animal" to cows, horses, etc., but not to, say, Belmag lamps. However, this store of information, which gives boundaries to the meaning-intention, seems to be a blind spot in Husserl's account, as he does not explain either what it is or how it is structured. Now, it seems legitimate to ask whether this store is in fact a sort of concept. Note that, as Husserl himself admits, the ambiguity of vague names is not a mere equivocation. Rather, the different meanings of vague names are intimately related to one another as members of one and the same genus. Husserl himself seems to point this out when he says that vague names apply to "correlative spheres comprehended in the same genus", or when he holds that the typical examples "stem from what are, or from what seem to be, genuinely unified fields." But then, isn't the store of information which allows us to "keep in mind" that these species have an intimate connection a generic concept ${ }^{6}{ }^{2}$ Recall that in contemporary philosophy, a type concept is a "rich arrays of information" stored in "long-term memory", and that "the subsets of features activated in each token use can vary" (Del Pinal 2016: 2912). In Husserl, one vague name means a series of "cognate or related" typical examples which vary according to the context. So could he deny that the information about the meaning of a word is stored in memory and forms a sort of concept?

In addition, Husserl has a problem with vagueness, which seems impossible to explain in his framework. That is, though he wants ordinary language to be vague, it is not clear how he can account for its vagueness. He tends to say that a vague name has various meanings, which change according to the context; however, the combination of various similar sharp concepts does not create vagueness (Sainsbury 2012). Think of a series of cookie cutters that you press on a pastry: you will end up having one or many bizarre forms, but nothing like vague boundaries. It seems then that if one wants to account for vagueness, one has to renounce sharp concepts, and introduce non-sharp ones which will allow for an open structure of relations of similarity. The early Husserl has no such concepts, and yet he speaks of "vague borders" and "transitional regions where application varies and is wholly uncertain", which

\footnotetext{
${ }^{6}$ See also Benoist 2010: 135, who emphasizes that "vague names" in the early Husserl are not mere equivocal terms, and that this hints at the acceptance of a non-standard type of concept from which their meaning is constructed. According to Benoist, the early Husserl in fact anticipates the prototype theory. In my opinion, the early Husserl would be unhappy with the admission of prototype concepts, although I think that they are an unavoidable consequence of his theory.
} 
seems to appeal to non-sharp conceptual contents. One way to explain this in the prototype theory is to hold that concepts have an undetermined "similarity comparison process" which is built into their very structure and which leads to vagueness: one compares cases to the prototype, and includes the more similar cases within the category, but without knowing where exactly inclusion should stop. This might explain Husserl's later introduction of type concepts: their specific structure is able to account for the fact that every type implies a "horizon of similarity" and is a "vague generality".

To conclude, in order to account for the kind of fluctuation of meaning-intentions that Husserl is interested in, the best move would be to accept concepts of a sort that very much resembles what contemporary philosophers and psychologists call "prototype concepts". Such a consideration might be among the reasons that led the later Husserl to hold that there are type concepts in addition to ideal concepts. ${ }^{8}$

\footnotetext{
${ }^{7}$ On how this "similarity comparison process" would be able to explain vagueness, see Barsalou 1987: 116, Margolis \& Laurence 2019, as well as Hampton 2007: 379. For more on this in Husserl's later account of types, see again my paper "The Structure and Domain of (Proto)type Concepts: A Husserlian Approach".

${ }^{8}$ This paper was written in the context of an Alexander von Humboldt postdoctoral fellowship on "Prototype Concepts in Austro-German Philosophy". A first draft of the paper was presented at the conference "Philosophy of Language in the Brentanian Tradition", held in 2018 at the University of Liège. I thank the participants for their comments, especially Kevin Mulligan, Sébastien Richard, and Basil Vassilicos. I am also grateful to Mark Textor for the discussion that we had on an earlier draft of this paper. Finally, I thank Charlotte Gauvry for her written comments on an earlier draft.
} 


\section{References}

Barsalou, L. W. 1987. "The Instability of Graded Structure: Implications for the Nature of Concepts". In Concepts and Conceptual Development: Ecological and Intellectual Factors in Categorization, ed. U. Neisser, 101-140. Cambridge: Cambridge University Press.

Bégout, B. 2002. "Un air de famille : la théorie husserlienne des types". Recherches husserliennes 17: 51-85.

Benoist, J. 2010. Concepts. Introduction à l'analyse. Paris: Cerf.

Del Pinal, G. 2016. "Prototypes as Compositional Components of Concepts". Synthese 193: $2899-2927$.

Erdmann, B. 1894. “Theorie der Typen-Einteilungen”. Philosophische Monatshefte 30/3-4: 15-49 and 129-158.

Hampton, J. A. 1995. "Concepts as Prototypes”. The Psychology of Learning and Motivation 46: 79-113.

—. 2007. "Typicality, Graded Membership, and Vagueness". Cognitive Science 31: 355384.

Husserl, E. 1939. Erfahrung und Urteil. Untersuchungen zur Genealogie der Logik, ed. L. Landgrebe. Prag: Akademia.

— 1984. Logische Untersuchungen. Zweiter Teil (Hua XIX/1-2), ed. U. Panzer. The Hague: Martinus Nijhoff (Trans. J.N. Findlay. London: Routledge, 1970).

- 2012. Zur Lehre vom Wesen und zur Methode der eidetischen Variation (Hua XLI), ed. D. Fonfara. New York: Springer.

Jerusalem, W. 1902. Lehrbuch der Psychologie. 3rd ed. Wien: Braumüller.

Lohmar, D. 1998. Erfahrung und Kategoriales Denken. Hume, Kant und Husserl über vorprädikative Erfahrung und prädikative Erkenntnis. Dordrecht: Kluwer. 
Margolis, E. and S. Laurence. 1999. "Concepts and Cognitive Science”. In Concepts: Core Readings, eds. E. Margolis and S. Laurence, 3-81. Cambridge, MA: MIT Press.

- 2019. “Concepts”. In Stanford Encyclopedia of Philosophy (Summer 2019 Edition), ed. E. N. Zalta. https://plato.stanford.edu/archives/sum2019/entries/concepts.

Marty, A. 1908. Untersuchungen zur Grundlegung der allgemeinen Grammatik und Sprachphilosophie. Erster Band. Halle: Niemeyer.

Meinong, A. 1969. “Abstrahieren und Vergleichen”. In Gesamtausgabe. Vol. 1, ed. R. Haller and R. Kindinger, 443-494. Graz: Akademische Druck- u. Verlagsanstalt.

Mulligan, K. 1990. "Marty's Philosophical Grammar". In Mind, Meaning and Metaphysics. The Philosophy and Theory of Language of Anton Marty, ed. K. Mulligan, 11-27. Dordrecht: Kluwer.

2012. Wittgenstein et la philosophie austro-allemande. Paris: Vrin.

Prinz, J. 2012. “Regaining Composure: A Defence of Prototype Compositionality”. In The Oxford Handbook of Compositionality, eds. W. Hinzen, E. Machery, and M. Werning, 437453. Oxford: Oxford University Press.

Recanati, F. 2012. "Contextualism: Some Varieties". In The Cambridge Handbook of Pragmatics, eds. K. Allen and K. M. Jaszczolt, 135-150. Cambridge: Cambridge University Press.

Rosch, E. and C. Mervis. 1975. "Family Resemblances: Studies in the Internal Structure of Categories". Cognitive Psychology 7: 573-605.

Roth, E. M. and E. J. Shoben. 1983. "The Effect of Context on the Structure of Categories". Cognitive Psychology 15: 346-378.

Sainsbury, R. M. (2012). “Concepts Without Boundaries”. In Vagueness: A Reader, eds. R. Keefe and P. Smith, 251-264. Cambridge, MA: MIT Press. 
Simons, P. M. 1995. "Meaning and Language". In The Cambridge Companion to Husserl, eds. B. Smith and D. W. Smith, 106-137. Cambridge: Cambridge University Press.

Taieb, H. 2020. "Ordinary Language Semantics: The Contribution of Brentano and Marty". British Journal for the History of Philosophy 28: 777-796.

—. Ms. "The Structure and Domain of (Proto)type Concepts: A Husserlian Approach".

Von Kries, J. 1916. Logik. Grundzüge einer kritischen und formalen Urteilslehre. Tübingen: Mohr.

Whewell, W. 1858. The History of Scientific Ideas. 2 vol. London: Parker.

Wittgenstein, L. 1953. Philosophical Investigations, ed. G.E.M. Anscombe and R. Rhees, trans. G.E.M. Anscombe. Oxford: Blackwell. 